\title{
South Coastal Community Development: Issues and Challenges
}

\section{Imamudin Yuliadi}

Faculty of Economics, Universitas Muhammadiyah Yogyakarta

Jl. Lingkar Barat, Tamantirto, Kasihan, Bantul, 55183 Yogyakarta Indonesia

Phone +62-274-387656, E-mail address: imamudin2006@yahoo.co.id

\begin{abstract}
Reality show that Indonesia is one country that have longest beach in the world. This fact give implication that economic potential of people life at the beach is important factor to indoors economic growth for improving walfare and equity economic development both national and regional scope. Research method that applied is desriptive investigative for obtain the fact about the economic problem of people at the beach especially beach potential economy for improving people economic welfare. Analitical methode at this research is location quotion $(L Q)$, shift-share, and typology klassen. The output of this research is making the planning model of promotion system and integrated investment to realize the equality of development economic at beach are in Yogyakarta.
\end{abstract}

Keywords: people empowerment model, integrated investment, beach area JEL Classification Codes: O1, R11

\section{Pembangunan Masyarakat Pesisir Selatan: Masalah dan Tantangannya}

\begin{abstract}
Abstrak
Kenyataan menunjukkan bahwa Indonesia merupakan salah satu negara yang memiliki pesisir terpanjang di dunia. Fakta ini memberikan implikasi bahwa potensi ekonomi masyarakat pesisir adalah faktor penting untuk pertumbuhan ekonomi, untuk meningkatkan kesejahteraan, dan pembangunan ekonomi yang adil baik dalam lingkup nasional maupun regional. Metode penelitian yang digunakan adalah diskriptif investigatif untuk memperoleh fakta tentang persoalan ekonomi masyarakat di pesisir terutama ekonomi potensi pantai untuk meningkatkan kesejahteraan ekonomi rakyat. Metode analitik pada penelitian ini adalah Location Quotion (LQ), Shift-share, dan Tipologi klassen. Output dari penelitian ini adalah pembuatan model perencanaan untuk sistem promosi dan investasi terpadu guna mewujudkan keadilan dalam pembangunan ekonomi di pesisir Yogyakarta.
\end{abstract}

Kata kunci: people empowerment model, integrated investment, beach area Kode Klasifikasi JEL: O1, R11 


\section{Pendahuluan}

Pembangunan di kawasan pesisir pantai memerlukan penanganan yang berbeda dibandingkan dengan kawasan lainnya mengingat kawasan pesisir pantai memiliki kekhasan baik ditinjau dari aspek geografi, geomorfologi, antropologi, ekonomi dan sosial. Perubahan kondisi alam yang relatif lebih ekstrim dibandingkan kawasan darat mendorong masyarakat melakukan aktivitas ekonomi dengan tingkat resiko yang lebih besar dengan kemungkinan mengalami kerugian yang juga lebih besar. Perlu ada kerjasama sinergis antara masyarakat setempat dengan instansi pemerintah yang terkait untuk menyelesaikan persoalan pembangunan ekonomi masyarakat yang tinggal di kawasan pesisir pantai. Wilayah pesisir selatan provinsi Daerah Istimewa Yogyakarta (DIY) merupakan daerah yang menyimpan potensi alam cukup besar untuk menopang pembangunan daerah dan peningkatan ketahanan pangan bagi masyarakat setempat dan daerah lainnya. Isu ini menjadi semakin menonjol sejak ada rencana pemerintah untuk membangun bandara bertaraf internasional di daerah Congot, kabupaten Kulonprogo, provinsi DIY. Diharapkan realisasi dari rencana pembangunan tersebut tidak hanya berdampak pada peningkatan pembangunan ekonomi yang dirasakan oleh kelompok masyarakat menengah atas dengan tumpuan modal yang besar tapi juga bisa dirasakan oleh masyarakat lapisan bawah secara lebih merata. Strategi dan pengembangan ekonomi terpadu daerah pesisir DIY adalah suatu bentuk alternatif model pengembangan ekonomi dalam menjawab tantangan untuk melaksanakan pembangunan perekonomian dan pengembangan daerah/ wilayah secara terpadu dan komprehensif, melalui pendekatan pengembangan potensi wilayah pesisir selatan DIY secara terpadu. Nelayan di DIY relatif jumlahnya tidak terlalu banyak namun memberikan kontribusi yang cukup baik dalam peningkatan taraf kesejahteraan nelayan dan juga dalam pemenuhan kebutuhan hasil tangkapan laut bagi masyarakat DIY dan sekitarnya. Nelayan DIY berdomisili di wilayah yang berbatasan langsung dengan wilayah pantai laut Hindia yaitu di kabupaten Bantul, kabupaten Kulonprogo dan kabupaten Gunungkidul. Sebagian besar kegiatan masyarakat yang bertempat tinggal di wilayah pesisir di samping melaut juga dengan melakukan kegiatan pengolahan hasil tangkapan ikan serta kegiatan sampingan lainnya seperti mengolah lahan pertanian.

\section{Metode Penelitian}

Untuk menjaga kredibilitas dan validitas hasil penelitian ini, maka disamping data diambil langsung dari obyek penelitian melalui survey di lapangan juga diambilkan dari sumber referensi yang dapat dipercaya (credible) baik dari buku-buku (referensi) yang diterbitkan secara internasional maupun terbitan nasional yang ada ISBN. Data-data diambil dari sumber yang kredibel seperti data dari dinas terkait seperti Bappeda, SKPD dan Dinas terkait yaitu Dinas Perindustrian dan Perdagangan (Diperindag), Dinas Pertanian (Dipertan), dan juga dari IFS, BPS, BI dan Bappenas. Tempat penelitian secara teknis di lokasi pantai selatan DIY namun secara prosedural data dan informasi tentang lokasi penelitian dapat diakses melalui media online yang dapat diungguh secara mudah.

Metode analisis dalam penelitian ini dilakukan dengan menggunakan beberapa metode analisis yaitu Analisis Location Quotient (LQ), Analisis Shift-Share, Analisis pemberdayaan ekonomi masyarakat. Analisis Shift-Share juga membandingkan perbedaan laju pertumbuhan berbagai sektor (industri) di daerah (kabupaten) dengan wilayah regional/nasional. Metode Shift-Share relatif lebih spesifik dibandingkan metode LQ karena dapat menjelaskan penyebab perubahan atas beberapa variabel. Analisis Shift-Share juga dapat untuk mengetahui proyeksi sektor ekonomi pada periode yang akan datang. Analisis Shift-Share bertujuan untuk mengetahui kontribusi tiap-tiap subsektor terhadap Pendapatan Domestik regional Bruto (PDRB). Analisis Shift-share dapat digunakan untuk mendeskripsikan trend agregat secara statistik, shift-share analisis mengklarifikasikan perubahan PDRB setiap saat dalam wilayah yang diperbandingkan dengan tiga kategori, komponen dalam mrembentuk shift-share 
diantaranya adalah PDRB di sektor tertentu (i) tingkat wilayah, laju pertumbuhan PDB tingkat nasional (rn), laju pertumbuhan PDB disektor tertentu (i) di tingkat nasional (rin), dan laju pertumbuhan PDRB di sektor tertentu (i) tingkat wilayah. Analisis Pemberdayaan Ekonomi Masyarakat yaitu suatu pendekatan yang digunakan dalam analisis pemberdayaan ekonomi masyarakat yaitu dengan mengkaji keadaan perekonomian daerah pedesaan secara partisipatif (participatory rural appraisal) atau PRA yang merupakan sekumpulan teknik dan alat yang mendorong masyarakat pantai untuk turut serta meningkatkan dan menganalisis pengetahuannya mengenai hidup dan kondisi mereka sendiri agar mereka dapat membuat rencana dan tindakan. Pendekatan lain dalam analisis pemberdayaan ekonomi masyarakat partisipatif yaitu metode-metode belajar secara partisipatif (partisipatory learning methods) atau PALM yang menekankan pada proses pembelajaran partisipatif masyarakat pedesaan dalam menghadapi permasalahan dan tantangan ekonomi. Identifikasi permasalahan dan rumusan strategi dalam pemecahan masalah berdasarkan proses partisipasi masyarakat. Location Quotient (LQ) merupakan alat analisis untuk mengetahui ada tidaknya spesialisasi suatu wilayah untuk sektor (industri) tertentu.

dimana,

$$
\mathrm{LQ}=\left(\mathrm{E}_{\mathrm{ij}} / \mathrm{E}_{\mathrm{j}}\right) /\left(\mathrm{E}_{\mathrm{in}} / \mathrm{E}_{\mathrm{n}}\right)
$$

$E_{i j}$ adalah Kesempatan kerja di sektor I di wilayah $j ; E_{j}$ adalah Kesempatan kerja di wilayah $\mathrm{j}$; $E_{\text {in }}$ adalah Kesempatan kerja di sektor I di negara $n$; $\mathbf{E}_{\mathrm{ij}}$ adalah Kesempatan kerja di negara $n$.

Interpretasi dari hasil perhitungan dengan formula tersebut adalah:

(1) Jika nilai LQ > 1, maka wilayah j untuk sektor I ada spesialisasi (Tingkat spesialisasi wilayah $>$ tingkat spesialisasi nasional)

(2) Jika nilai $L Q=1$, maka wilayah j untuk sektor I ada spesialisasi (Tingkat spesialisasi wilayah $=$ tingkat spesialisasi nasional)

(3) Jika nilai $L Q<1$, maka wilayah j untuk sektor I ada spesialisasi (Tingkat spesialisasi wilayah < tingkat spesialisasi nasional)

Analisis LQ menunjukan bahwa seluruh kota/kabupaten baik yang berada dalam kawasan andalan maupun kawasan bukan andalan, memiliki LQ yang lebih besar dari satu pada beberapa subsektor lapangan usaha. Artinya, semua kabupaten/kota memiliki subsektor unggulan dan penetapan kawasan andalan berdasarkan persyaratan sektor unggulan dapat dipandang tepat.

Dalam analisis Typology Klassen dibagi menjadi 4 kategori yaitu daerah maju berkembang cepat, daerah berkembang cepat, daerah potensial dan daerah relatif tertinggal. Dalam analisis Typology Klassen dibagi menjadi 4 kategori yaitu:

a. Daerah Maju Berkembang Cepat: Daerah yang memiliki ciri Kontribusi PDRB Kab/kota/ Rerata Kontribusi PDRB provinsi $\geq 1$ dan Rerata Pertumbuhan PDRB (kab/Kota)/Rerata PDRB Provinsi $\geq 1$

b. Daerah Berkembang Cepat: Daerah yang memiliki cirri Kontribusi PDRB Kab/kota/ Rerata Kontribusi PDRB provinsi $\leq 1$ dan Rerata Pertumbuhan PDRB (kab/Kota)/Rerata PDRB Provinsi $\geq 1$

c. Daerah Potensial: Daerah yang memiliki ciri Kontribusi PDRB Kab/kota/Rerata Kontribusi PDRB provinsi $\geq 1$ dan Rerata Pertumbuhan PDRB (kab/Kota)/Rerata PDRB Provinsi $\leq 1$

d. Daerah Relatif Tertinggal: Daerah yang memiliki ciri Kontribusi PDRB Kab/kota/ Rerata Kontribusi PDRB provinsi $\leq 1$ dan Rerata Pertumbuhan PDRB (kab/Kota)/Rerata PDRB Provinsi $\leq 1$

\section{Hasil dan Pembahasan}

Struktur ekonomi dan struktur sosial tiap kabupaten di DIY berbeda satu sama lain yang didasarkan pada Typology Klassen. Berdasarkan laju pertubuhan PDRB dan kontribusi dalam pembentukan PDRB kabupaten terhadap PDRB provinsi dapat dikelompokan menjadi beberapa kategori. Perkembangan Ekonomi Kabupaten/ Kota terhadap Daerah Istimewa Yogyakarta Tahun 2007-2011 sebagaimana dalam Tabel 1.

Hasil analisis memperlihatkan bahwa daerah yang sudah maju dan berkembang cepat adalah kota Yogyakarta, temuan ini tidak mengherankan karena kota Yogyakarta merupakan penggerak perekonomian DIY. 
Tabel 2. Perkembangan Ekonomi Daerah DIY berdasarkan Typology Klassen

\begin{tabular}{ll}
\hline Kriteria & Daerah \\
\hline Daerah Maju Berkembang Cepat & Kota Yogyakarta \\
Daerah Berkembang Cepat & Kabupaten Bantul \\
Daerah Potensial & Kabupaten Sleman \\
Daerah Tertinggal & Kabupaten Gunung \\
& kidul, Kabupaten \\
& Kulonprogo \\
\hline Sumber: DIY dalam angka 2007-2011 (diolah)
\end{tabular}

Sedangkan kabupaten Bantul masuk dalam kategori daerah berkembang cepat, artinya memiliki potensi pengembangan yang cukup besar untuk menjadi daerah yang lebih maju. Kabupaten Sleman masuk dalam kategori daerah potensial yang memerlukan investasi dan strategi pembangunan yang besar untuk mendorong pertumbuhan ekonominya. Sedangkan kabupaten Gunungkidul dan Kulonprogo masuk dalam kategori daerah tertinggal dalam konteks pembangunan ekonomi DIY mengingat potensi ekonominya yang relatif rendah dan minimnya pusat-pusat pertumbuhan ekonomi.

Location Quotient (LQ) merupak an alat analisis untuk mengetahui ada tidaknya spesialisasi suatu wilayah untuk sektor (industri) tertentu.

$\mathrm{LQ}=\left(\mathrm{E}_{\mathrm{ij}} / \mathrm{E}_{\mathrm{j}}\right) /\left(\mathrm{E}_{\mathrm{in}} / \mathrm{E}_{\mathrm{n}}\right)$

dimana,

$\mathrm{E}_{\mathrm{ij}}$ : Kesempatan kerja di sektor I di wilayah $\mathrm{j}$

$E_{j}:$ Kesempatan kerja di wilayah $j$

$\mathrm{E}_{\text {in }}$ : Kesempatan kerja di sektor I di negara $\mathrm{n}$

$\mathrm{E}_{\mathrm{ij}}$ : Kesempatan kerja di negara $\mathrm{n}$

Analisis LQ menunjukan bahwa seluruh kota/kabupaten baik yang berada dalam kawasan andalan maupun kawasan bukan andalan, memiliki LQ yang lebih besar dari satu pada beberapa subsektor lapangan usaha. Artinya, semua kabupaten/kota memiliki subsektor unggulan dan penetapan kawasan andalan berdasarkan persyaratan sektor unggulan dapat dipandang tepat.

Dari data di atas dapat disimpulkan bahwa masing-masing kabupaten/kota memiliki sub sektor unggulan tertentu yaitu pada sektor yang memiliki nilai LQ $>1$. Kabupaten Sleman memiliki sektor unggulan pada sektor-sektor di Industri pengolahan, Bangunan, Perdagangan, restoran dan hotel, keuangan, persewaan, dan jasa perusahaan, serta jasa-jasa. Hal ini bisa dilihat dari hasil analisis LQ yang nilainya $>1$, sedangkan sektor lainnya seperti pertanian, pertambangan dan penggalian dan angkutan dan komunikasi nilainya $<1$ sehingga bukan merupakan sektor unggulan. Aspek ekonomi yang perlu diperhatikan dari hasil analisis LQ tersebut yaitu pada sektor pertanian, karena selama ini sektor pertanian termasuk sektor yang menjadi kebanggaan masyarakat seperti salak pondoh dan agrowisata. Fenomena ini menjadi indikasi bahwa terjadi alih fungsi lahan yang cukup signifikan untuk penggunaan non pertanian karena kebutuhan ekonomi yang cukup menjanjikan misalnya untuk perumahan (real estate), ruko dan pembangunan sarana bisnis. Sedangkan kondisi yang berkebalikan terjadi antara kota Yogyakarta dengan kabupaten Gunungkidul dan Bantul yang masingmasing memiliki keunggulan pada sektorsektor tertentu. Kota Yogyakarta dan juga kabupaten Sleman memiliki keunggulan pada

Tabel 3. Nilai Location Quotion (LQ) Perekonomian DIY

\begin{tabular}{llllll}
\hline Sektor Ekonomi & \multicolumn{5}{c}{ Rerata Location Quotion (LQ) } \\
\hline & Yogyakarta & Bantul & Kulonprogo & Sleman & Gunungkidul \\
Pertanian & 0,01852 & 1,33 & 1,52 & 0,9025 & 2,18 \\
Pertambangan dan Penggalian & 0,00714 & 1,36 & 1,30 & 0,7095 & 2,57 \\
Industri Pengolahan & 0,78396 & 1,21 & 1,11 & 1,0969 & 0,81 \\
Listrik, gas dan air bersih & 1,04143 & 0,74 & 0,54 & 0,7571 & 0,46 \\
Bangunan & 0,82524 & 1,23 & 0,54 & 1,1960 & 0,88 \\
Perdagangan, restoran dan hotel & 1,19414 & 0,94 & 0,82 & 1,0736 & 0,70 \\
Angkutan dan Komunikasi & 1,92354 & 0,69 & 0,98 & 0,5754 & 0,67 \\
Keuangan, Persewaan dan & & & & & 0,51 \\
Jasa Perusahaan & 1,50558 & 0,67 & 0,68 & 1,1161 & 0,51 \\
Jasa-jasa & 1,22672 & 0,79 & 1,04 & 1,0321 & 0,79 \\
\hline
\end{tabular}

Sumber: DIY dalam angka 2007-2011 (diolah) 
sektor ekonomi sekunder dan tersier sedangkan kabupaten Gunungkidul dan Bantul memiliki keunggulan pada sektor primer.

Analisis shift-share bertujuan untuk mengetahui kontribusi tiap-tiap subsektor terhadap Pendapatan Domestik Regional Bruto (PDRB). Analisis Shift-share dapat digunakan untuk mendeskripsikan trend agregat secara statistik, shift-share analisis mengklarifikasikan perubahan PDRB setiap saat dalam wilayah yang diperbandingkan dengan tiga kategori, komponen dalam membentuk shift-share di antaranya adalah PDRB di sektor tertentu (i) tingkat wilayah, laju pertumbuhan PDB tingkat nasional (rn), laju pertumbuhan PDB di sektor tertentu (i) di tingkat nasional (rin), dan laju pertumbuhan PDRB di sektor tertentu (i) tingkat wilayah (rij).Komponen perubahan secara nasional mempresentasekan komponen pembagian nasional untuk perhitungan dimana laju pertumbuhan regional yang telah mengalami perubahan diikuti perubahan secara tepat dalam tingkat nasional untuk semua sub sektor dalam tingkat nasional untuk semua sub sektor dalam periode penilaian. Jika pertumbuhan di tingkat regional berbeda dengan nasional (berupa positip atau negatif dalam pergeseran PDRB), secara total pergeseran terdiri dari pergeseran struktural juga pergeseran mengenai pembagian proporsional. Dampak perubahan PDRB dimana dalm perhitungan di tingkat regional berubah sesuai dengan tipe dari PDRB dalam sub sektor tertentu (termasuk cepat atu lambatnya laju pertumbuhan nasional). Pergeseran terdiri dari perbedaan dalam pergeseran juga pengetahuan tentang dampak regional dimana perhitungan PDRB regional berubah seiring dengan faktor lokasi di tiap regional. Berikut dijelaskan hasil perhitungan analisis shift-share (Tabel 4).

Dari Tabel 4, terlihat pada tahun 2011 terjadi perbedaan karakteristik pembangunan ekonomi antarkabupaten/kota di DIY, artinya bahwa masing-masing daerah memiliki keunggulan dan keunikan ekonominya sendirisendiri. Di samping itu juga menunjukkan adanya fenomena pergeseran pembangunan antar sektoral yang dapat dilihat dari laju pertumbuhan yang signifikan, demikian juga dapat dilihat kecenderungan perubahan karakter ekonomi antar sektor.

Di kota Yogyakarta terlihat bahwa keunggulan kompetitif mengalami penurunan terutama di sektor keuangan, persewaan dan jasa perusahaan serta jasa-jasa(akibat krisis Eropa dan Amerika). Hasil analisis shift-share pada tahun 2011 secara keseluruhan dengan melihat analisis shift-share pada PDRB mengalami perbaikan dibandingkan dengan tahun 2010, secara keseluruhan semua sektor terjadi peningkatan keunggulan kompetitif dibandingkan tahun 2010 pada PDRB dalam wilayah kota Yogyakarta. Sektor-sektor yang mengalami peningkatan keunggulan kompetitif adalah perdagangan, restoran dan hotel, angkutan dan komunikasi dan jasa-jasa. Sektor-sektor tersebut relatif stabil pengaruh keunggulan kompetitif dalam perekonomian di kota Yogyakarta. Perubahan shift-share dari tahun 2009-2011 mengalami fluktuasi secara total dan pada umumnya mengalami penurunan kinerja tahun 2011 dibandingkan dengan tahun 2009. Analisis

Tabel 4. Nilai Shift-Share Perekonomian DIY

\begin{tabular}{llllll}
\hline Sektor Ekonomi & \multicolumn{4}{c}{ Nilai Shift-Share tahun 2011 } & \\
& Yogyakarta & Bantul & Kulonprogo & Sleman & Gunungkidul \\
\hline Pertanian & 416 & 21,809 & 11,768 & 23,788 & 30,212 \\
Pertambangan dan Penggalian & 15 & 2,023 & 80 & 1,815 & 3,376 \\
Industri Pengolahan & 30,93 & 35,620 & 13,833 & 50,657 & 20,032 \\
Listrik, gas dan air bersih & 3,23 & 1,746 & 55 & 2,872 & 910 \\
Bangunan & 24,19 & 26,864 & 5,553 & 42,825 & 16,536 \\
Perdagangan, restoran dan hotel & 101,81 & 59,768 & 23,467 & 109,087 & 36,903 \\
Angkutan dan Komunikasi & 174,22 & 44,868 & 27,188 & 58,941 & 35,598 \\
Keuangan, Persewaan dan & & & & & \\
Jasa Perusahaan & $-295,34$ & $-98,176$ & $-41,329$ & $-249,477$ & $-61,959$ \\
Jasa-jasa & 70,26 & 33,203 & 19,825 & 67,965 & 27,569 \\
\hline
\end{tabular}

Sumber: DIY dalam angka 2007-2011 (diolah) 
shift-share tersebut juga dapat menjadi bahan evaluasi terhadap proses perencanaan pembangunan di kota Yogyakarta yang mengalami perubahan karakteristik dari perekonomian sektor primer ke sektor jasa. Sementara untuk daerah lainnya menunjukkan kecenderungan yang agak berbeda seperti di kabupaten Bantul. Hasil analisis shift-share pada tahun 2011 secara keseluruhan dengan melihat analisis shift-share pada PDRB mengalami perbaikan dibandingkan dengan tahun 2010, tetapi secara keseluruhan semua sektor terjadi penurunan keunggulan kompetitif dibandingkan tahun 2010 pada PDRB dalam wilayah Kabupaten Bantul. Analisis di atas mengungkapkan bahwa pengaruh pertumbuhan provinsi (Nij) pada tahun 2011 yang paling besar adalah sektor pertanian di ikuti sektor perdagangan, restoran dan hotel masing-masing sebesar 46,195 dan 42,157. Hasil ini selaras dengan analisis Klasen Typology dan analisis struktur ekonomi kabupaten Bantul, karena memang secara obyektif kabupaten Bantul merupakan daerah yang subur dan potensial bagi pengembangan sektor pertanian dan peternakan.

Analisis pemberdayaan masyarakat nelayan di pesisir pantai selatan DIY menunjukkan kecenderungan yang terus membaik dimana hasil tangkapan dan nilai tambah produk perikanan terus menunjukkan kecenderungan meningkat. Kondisi ini tidak terlepas dari peran aktif masyarakat nelayan untuk meningkatkan ketrampilan dan jaringan kerjasama termasuk dalam meningkatkan nilai ekonomi hasil tangkapan ikan. Modernisasi peralatan tangkap ikan seperti kapal dan jaring serta peningkatan teknik pengelolaan hasil tangkapan serta pengolahan hasil tangkapan sehingga dapat laku di pasaran merupakan aktivitas yang secara riil dapat meningkatkan pendapatan dan kesejahteraan nelayan pesisir selatan DIY. Peningkatan hasil tangkapan ikan dan pendapatan nelayan juga didorong oleh meningkatnya kerjsama antarnelayan melalui organisasi kelompok nelayan untuk mengembangkan nilai ekonomi hasil tangkapan dan kesejahteraan keluarga nelayan. Selain membentuk kelompok nelayan tangkap juga terdapat kelompok usaha bersama (KUB) pengolah hasil tangkapan ikan dan pedagang ikan yang anggota para pedagang ikan sebagaimana produksi yang dihasilkan dari TPI Pandan Mino yang mencapai $375 \mathrm{~kg} /$ hari atau 11.200 $\mathrm{kg} /$ bulan dengan jenis komoditas tangkapan. Pada Tabel 5 ditampilkan data hasil tangkapan ikan di TPI Pandan Minoi.

Tabel 5 menjelaskan bahwa komoditas yang dihasilkan adalah berbagai macam jenis ikan yang mempunyai nilai ekonomi tinggi dan kemudian diolah menjadi ikan goreng, ikan asam manis dan olahan hasil tangkapan laut lainnya. Kebutuhan bahan baku ikan segar masih didatangkan dari luar pantai DIY. Jadi sebenarnya potensi pengembangan sektor perikanan DIY masih cukup besar baik kebutuhan bahan baku ikan untuk mendorong industri pengolahan ikan atau untuk memenuhi kebutuhan permintaan ikan segar yang jumlah-

Tabel 5. Hasil Tangkapan Ikan Nelayan di Tempat Pelelangan Ikan (TPI) Pandan Mino, Bantul

\begin{tabular}{ll}
\hline Jenis Ikan & Jumlah (kg/tahun) \\
\hline Bawal & 13.692 \\
Layut & 9.108 \\
Kakap & 1.368 \\
Tengiri & 88 \\
Hiu & 1.156 \\
Pari & 3.200 \\
Keting & 8.284 \\
Gatho & 208 \\
Tongkol & 80.000 \\
Ekor Kuning & 728 \\
Teri & 6.024 \\
Campur & 7.944 \\
Surung & 156 \\
Samanganti & $3.357,2$ \\
\hline
\end{tabular}

Sumber: Profil Tempat Pelalangan Ikan (TPI) DIY, 2013 
nya terus meningkat. Sedangkan kelompok pedagang ikan juga memberikan kontribusi ekonomi yang cukup besar dalam meningkatkan nilai ekonomi hasil tangkapan ikanikan segar yang langsung diolah di tempat. Potensi pengembangan sektor perikanan juga mendorong berkembangnya sektor pariwisata laut dan pantai karena adanya sentra penjualan hasil tangkapan ikan akan menjadi daya tarik bagi wisatawan asing dan domestik untuk datang ke pantai disamping menikmati keindahan laut untuk untuk menikmati hasil tangkapan ikan baik untuk dikonsumsi di tempat atau di bawa pulang seperti di Baron, Depok, Congot, Glagah, Krakal dan Parangtritis. Perkembangan pariwisata pantai di DIY seiring dengan perkembangan sektor perikanan laut dan sekaligus juga dapat meningkatkan pendapatan dan kesejahteraan masyarakat nelayan.

\section{Simpulan}

Dari hasil penelitian di atas dapat diperoleh beberapa kesimpulan yaitu:

1. Pengembangan sektor perikanan di DIY membutuhkan perencanaan dan pengembangan yang komprehensif dan integral dari semua stakeholders baik pemerintah, nelayan, masyarakat dan dunia usaha

2. Pengembangan sektor perikanan harus diorientasikan untuk meningkatkan kesejahteraan keluarga nelayan melalui peningkatan hasil tangkapan dan nilai ekonomi hasil tangkapan ikan

3. Peningkatan hasil tangkapan ikan melalui peningkatan kualitas dan kapasitas peralatan tangkap ikan baik melalui program modernisasi kapal dan peralatan jaring sehingga dapat menjangkau cakupan laut yang lebih jauh.

4. Peningkatan pendapatan dan kesejahteraan nelayan melaui peningkatan nilai ekonomi hasil tangkapan dengan teknologi penyimpanan dan pengolahan ikan menjadi produk-produk yang diminati pasar

5. Pengembangan sektor perikanan yang terpadu dengan pengembangan sektor pariwisata dan pertanian lahan pantai untuk memberi peluang ekonomi lebih banyak kepada nelayan
6. Perlu dibuat roadmap pengembangan sektor perikanan dalam jangka menengah dan jangka panjang menyongsong pembangunan bandara internasional di Kulonprogo agar dapat memberikan peran lebih besar bagi sektor perikanan dalam roda ekonomi di DIY.

\section{Daftar Pustaka}

Arkema, pK. K., Abramson, S. C. and Dewsbury, B.M. 2006. Marine Ecosystem-Based Management: from Characterization to Implementation. Frontiers in Ecology and the Environment, 4(10), 525-532. www. mendeley.com/.../marine-ecosystembasedmanagement-from-characterization-to-implementation/- Amerika Serikat. Diakses tanggal 18 Oktober 2009.

Arsyad Anwar. 1985. Prospek dan Permasalahan Ekonomi Indonesia 1985-1986, edisi pertama. Jakarta: Fakultas Ekonomi Universitas Indonesia dan Sinar Harapan.

Boediono, 1979, Econometric Models of The Indonesian Economy for Short Run Policy Analysis, Disertation Ph.D, University of Pensylvania.

Dinc Mustafa, 2001, Regional and Local Economic Analysis Tools, The World Bank, Washington DC.

Firman, T. 1997. Land Convertion and Urban Development in The Northern Region of West Java, Indonesia, Urban Studies, 34 (7): 1027-1046.

Hill, Hall. 1996. The Indonesian Economic since 1966 Southeast Asia's Emerging Giant, London: Cambridge University Press.

IMF. 1998. World Economic Outlook, May, Washington DC: International Monetary Fund.

Imamudin Yuliadi. 2001. Analisis Makroekonomi Indonesia Pendekatan IS-LM, tesis. Yogyakarta: Universitas Gadjah Mada.

Insukendro. 1990. "Komponen Koefisien Regresi Jangka Panjang Model Ekonomi Studi Kasus Impor Barang di Indonesia", 
Journal Ekonomi dan Bisnis Indonesia, No. 2 tahun $V$.

Insukendro. 1992. Pembentukan Model dalam Penelitian Ekonomi. Jurnal Ekonomi dan Bisnis Indonesia, tahun VII, No. 1

Kustiawan, A. 1997. Konversi Lahan Pertanian Pantai Utara Pulau Jawa, Prisma No. 1 tahun XXVII, Jakarta: LP3ES.

Maddala, GS. 2001. Introduction to Econometrics, second edition, New York: Maxwell Macmillan International Publishing Company.

Mankiw. 2000. Macroeconomics. New York: Worth Publisher Co.

M. Nasir, 1999. Metode Penelitian. Jakarta: Ghalia Indonesia.

Nopirin. 1983. A Synthesis of Monetary and Keynesian Approach to The Balance of Payments The Indonesian Case 1970-1979, Ph.D disertation, Washington State University, 1983, Unpublished

Peursen van CA. 1993. Susunan Ilmu Pengetahuan Sebuah Pengantar Filsafat Ilmu. Jakarta: PT Gramedia.

Pindyck, Robert S and Rubinfeld, Daniel L. 1991. Econometric Model and Economic Forecast, International edition, McGraw-Hill Inc., third edition.

Sadoulet Elisabeth and Alain de Janvry. 1995. Quantitative Development Policy Analysis, Baltimore: The John Hopkins University Press.

Soekartawi. 1994. Peran Sektor Pertanian dalam Perekonomian Indonesia, Jurnal Studi
Indonesia, 4 http://pk.ut.ac.id/jsi/ 4soeka.htm (2 April 2006)

Sritua Arif. 1990. Dari Prestasi Pembangunan sampai Ekonomi Politik, kumpulan Karangan, Penerbit Universitas Indonesia

Supono Prasetyo, 2003, Analisis Shift-Share Perkembangan dan Penerapan, Jurnal Ekonomi dan Bisnis, FE-UGM, Yogyakarta, Tawang Alun, 1992, Analisis Ekonomi Utang Luar Negeri, Jakarta: LP3ES.

Thomas, R Leighton, 1985, Introductory Econometrics Theory and Application, first edition, British Library Catalog in Publishing Data, Printed in Singapore.

Turnovsky, Stephen J. 1981. Macroeconomic Analysis and Stabilization Policy, Cambridge University Press, USA.

Tulus Tambunan. 2001, Perdagangan Internasional dan Neraca Pembayaran. Jakarta: LP3ES.

West and Cho. 1995. The Predictive Ability of Several Models of Exchange Rate Volatility. Journal of Econometrics, 69, , pp. 367391.

Wihana Kirana Jaya. 1990. Seleksi Model Permintaan Uang di Indonesia 1973-1983. Journal Ekonomi dan Bisnis Indonesia, No. 2 tahun $V$.

Zhaoyong Zhang. 1999. China's Exchange Rate Reform and Its Impact on The Balance of Trade and Domestic Inflation. Asia Pacific Journal of Economics and Business, vol. 3 No. 2, December. 